\title{
User-Calibration of Mettler AT200 Analytical Balance
}

\author{
J. Estill
}

July 2, 1996

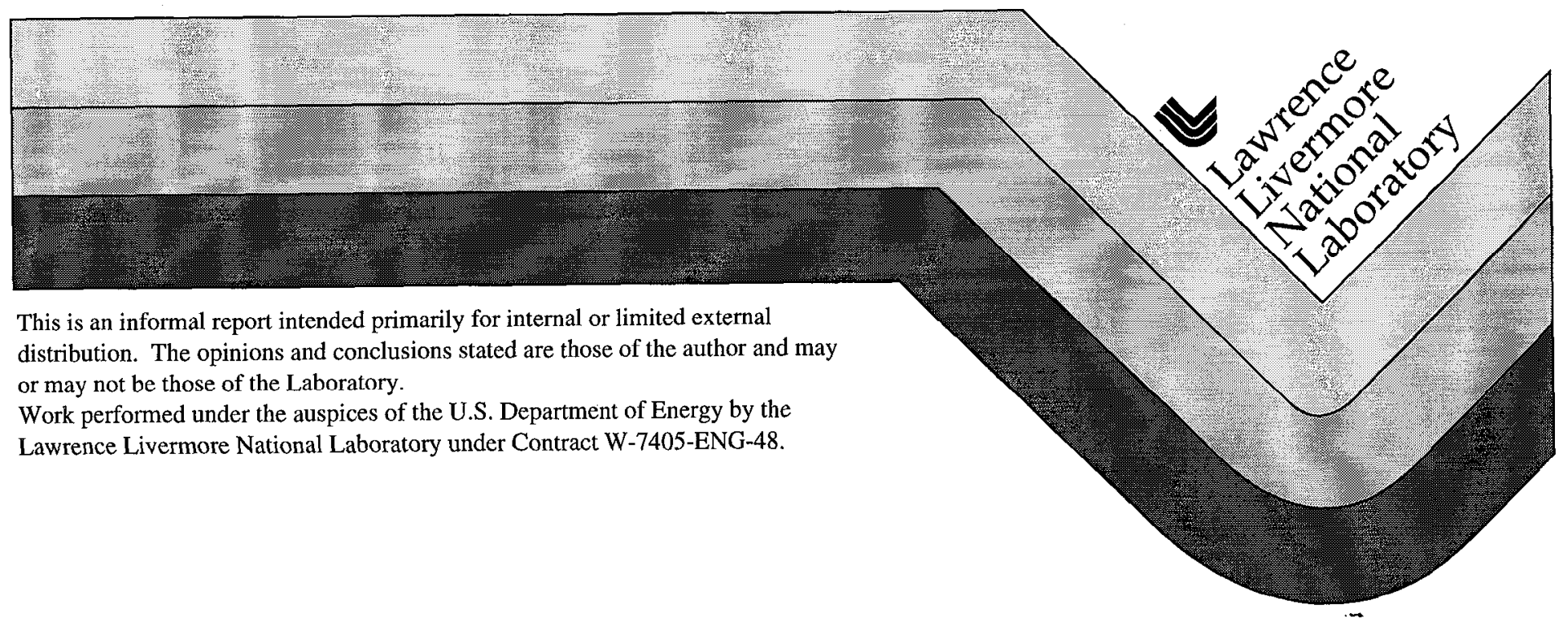




\section{DISCLAIMER}

This document was prepared as an account of work sponsored by an agency of the United States Government. Neither the United States Government nor the University of California nor any of their employees, makes any warranty, express or implied, or assumes any legal liability or responsibility for the accuracy, completeness, or usefulness of any information, apparatus, product, or process disclosed, or represents that its use would not infringe privately owned rights. Reference herein to any specific commercial product, process, or service by trade name, trademark, manufacturer, or otherwise, does not necessarily constitute or imply its endorsement, recommendation, or favoring by the United States Government or the University of California. The views and opinions of authors expressed herein do not necessarily state or reflect those of the United States Covernment or the University of California, and shall not be used for advertising or product endorsement purposes.

This report has been reproduced directly from the best available copy.

Available to DOE and DOE contractors from the Office of Scientific and Technical Information

P.O. Box 62, Oak Ridge, TN 37831

Prices available from (423) 576-8401

Available to the public from the

National Technical Information Service

U.S. Department of Commerce

5285 Port Royal Rd.,

Springfield, VA 22161 
University of California

Lawrence Livermore

National Laboratory

YUCCA MOUNTAIN PROJECT

Technical Implementing Procedure

Subject:

User-Calibration of Mettler AT200 Analytical Balance

Revision: $\quad 0$

Effective Oate:

Page: $\quad 1$ of 5

AUTHOR:

J. Estill

Training Required: Yes $\mathrm{No}$

Comments:

Training required for personnel performing work to this TIP.

REVISION HISTORY

Rev. No. CN No. Effective Date Description of Bevision/CN

0

07/02/96

Initial Issue

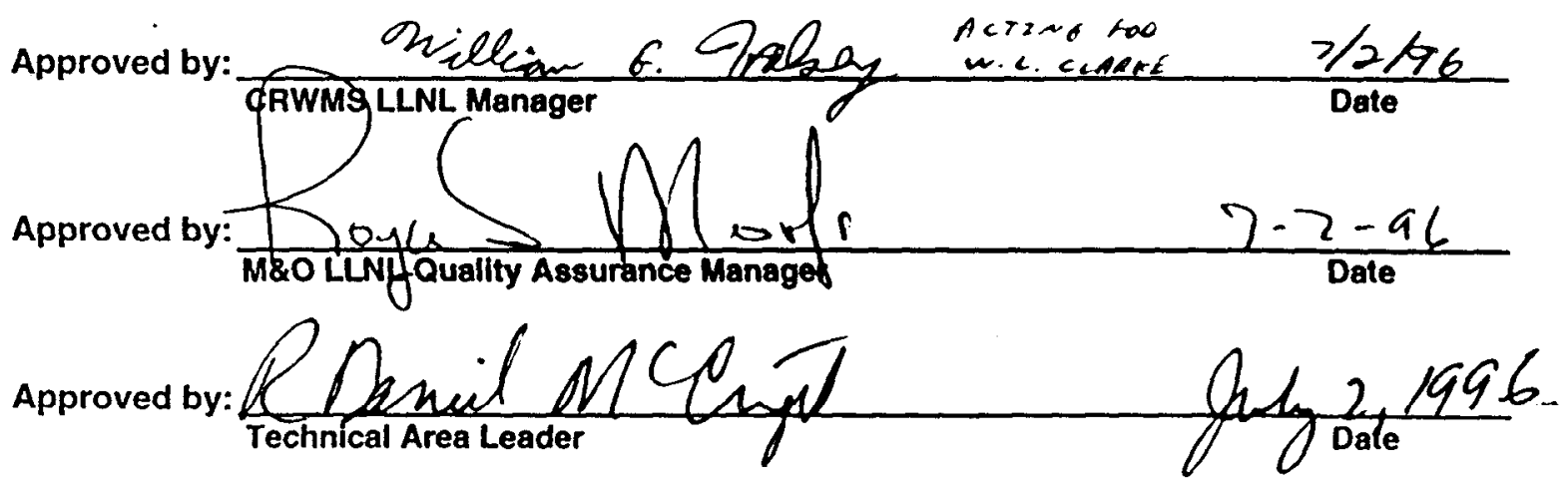




\begin{tabular}{|l|l|l|l|l|}
\hline No.: & Revision: & Pate: & Page: \\
& 0 & $07 / 02 / 96$ & 2 & of \\
\hline
\end{tabular}

\subsection{PURPOSE}

The purpose of this technical implementing procedure (TIP) is to describe the calibration of the Mettler AT200 analytical balance or similar type balance (henceforth called the 'balance'). This balance is used for activities of the Scientific Investigation Plan (SIP) "Metal Barrier Selection and Testing" (SIP. CM-01, WBS \# 1.2.2.5.1). In particular, it will be used for Activity E-20-50, "Long-Term Corrosion Studies." The balance will be used for weighing test specimens and reagent chemicals. However, it is not limited to these uses.

The calibration procedures consist of activating the internal (self) calibration of the apparatus, and weighing and recording of traceable standards. The balance is equipped with self (internal) calibration and linearization capabilities. It has an internal (built in) set of weights which are used for self calibration. The standard weights are traceable to National Institute of Standards and Technology (NIST).

\subsection{SCOPE}

This procedure describes the methodology for calibration of a Mettler AT200 analytical balance or similar type balance. NIST traceable weights are employed in the calibration procedure.

\subsection{RESPONSIBILITIES}

The Principal Investigator (PI) or designee is responsible for the conduct of the activities and methods described in this procedure, and maintaining scientific notebooks and/or electronic recording media.

The Technical Area Leader (TAL) is responsible for verifying that this procedure meets the objectives of SIP "Metal Barrier Selection and Testing" (SIP-CM-01, WBS \# 1.2.2.5.1), and the Activity Plan for E-2050, "Long-Term Corrosion Studies."

The YMP Quality Assurance Manager is responsible for monitoring the implementation of this TIP and for assuring the continuing effectiveness of the applicable controls.

\subsection{EQUIPMENT}

A. Analytical Balance Mettler AT200 Serial \# 1114463500 or similar type balance. A copy of the operating manual will be maintained with the balance.

B. NIST traceable weights Troemner Weight Set (no serial number) 0.005 grams to 100 grams. Certified by Sandia National Laboratories, Standards Laboratory Certificate. Recall No. 4935818, date tested: June 13, 1996, expires on June 13, 1999. (see Appendix) 


\begin{tabular}{|l|l|l|l|l|l|}
\hline No: & Revision: & Date: & Page: & \\
TIP-CM-04 & 0 & $07 / 02 / 96$ & of & 5 \\
\hline
\end{tabular}

\subsection{ANALYTICAL BALANCE OPERATIONS}

Note: A schematic of the balance is shown in Exhibit 1, with features of the balance labeled numerically. The numbered features referred to in the following paragraphs will be in italics.

A. Tuming on balance: depress key 1 "Re-Zero", "Set", "On/Off". (The balance must warm up for at least 5 minutes if starting from a cold start before proceeding to any other operation.)

B. Leveling of balance: adjust the two screw feet 24 at the rear of the balance housing so that the air bubble is in the middle of level 17

\subsection{FREQUENCY OF CALIBRATION}
A. Calibration shall be performed on the day the specimens are weighed.
B. Different users shall calibrate the balance and shall not rely on the calibration of others.

\subsection{CALIBRATION PROCEDURES}

The calibration procedures follow those recommended by the manufacturer [Mettler, 1994].

\subsection{Record traceable standards information}

Record certified weights, including tolerances, of the standards used in the calibration. Also include certification numbers, the standards laboratory, and any other pertinent information. Note that once this information is entered into a particular scientific notebook or specific electronic database it does not need to be re-entered each time the balance is calibrated.

\subsection{Initial calibration}

A. Tum on the balance.

B. Ensure that the balance is levelled.

C. Activate the balance to perform its self calibration.

1) Repeatedly press the "Menu" key 3 until "AUTOCAL; CAL int" appears on the display 25 and 26.

2) Trigger the calibration procedure by pressing the "Set" key 1. Ensure that the draft shield 8 is closed.

The balance signals the user that the calibration and linearization are complete when " $\mathrm{CAL}$ End" appears in the display 25 and the beep sounds. The balance returns to the weighing mode at this time. 


\begin{tabular}{|l|l|l|l|l|l|}
\hline No.: & Revision: & Pate: & Page: \\
TIP-CM-04 & 0 & $07 / 02 / 96$ & 4 & 5 \\
\hline
\end{tabular}

D. Weigh certified weight(s) in the balance. The weights are chosen to encompass the nominal weights of the specimens to be weighed.

1) Zero the balance by pressing the "Re-Zero" key 1 . The draft shield closes and the balance zero itself. The balance beeps, and then the draft shield opens when zeroing is complete.

2) Load the weights, close draft shield 8, and press the "Print" key 6. When the weighing is complete a beep sounds, the draft shield opens, and the weight is displayed for 5 seconds.

3) If the balance is connected electronically to computer, pressing the "Print" key 6 will also activate data transfer. If the balance is not connected to a computer, the user will record the readings in the scientific notebook.

7.3 In process recalibration of the balance.

The balance has the feature that it will calibrate and linearize itself as soon as it detects a change in the local conditions which warrants recalibration. The unit notifies the user that the recalibration is required when "AUTOCALIN" appears in the display 25. When this occurs, the user will terminate what he/she is doing, and will perform the following recalibration procedure.

Activate the balance to perform its self calibration by

A. Repeatedly pressing the "Menu" key 3 until "AUTOCAL; CAL int" appears on the display $25 \& 26$.

B. Triggering the calibration procedure by pressing the "Set" key 1. Ensure that the draft shield 8 is closed.

The balance signals the user that the calibration and linearization are complete when "CAL End" appears in the display 25 and the beep sounds. The balance returns to the weighing mode at this time.

\subsection{Recording of traceable weight standards at completion of task.}

At the completion of a task or portion of a task, measurement of the same weights used in step 7.2(D) will be repeated and recorded in the appropriate file of an electronic database or the scientific notebook.

\subsection{OUT OF CALIBRATION}

Out of calibration equipment will be handled as specified by QP 12.0, "Control of Measuring and Test Equipment". If the absolute weights of standards differ by more than $\pm 0.001 \mathrm{~g}$ from the readings of the balance, then the balance cannot be used for this activity until it is repaired and reads within the acceptable range. 


\begin{tabular}{|l|l|l|l|l|}
\hline No.: & Revision: & Page: & ate: \\
TIP-CM-04 & 0 & $07 / 02 / 96$ & 5 & of \\
\hline
\end{tabular}

If there is a drift of the weight readings of the standard weights of more than $\pm 0.001 \mathrm{~g}$, then the unit can not be used in this activity.

\subsection{TRAINING}

Personnel responsible for the measurement of test specimens in the applicable activities of SIP "Metal Barrier Selection and Testing" (SIP-CM-01, WBS \# 1.2.2.5.1) shall be trained to this TIP. In particular, this TIP applies to Activity E-20-50, "Long-Term Corrosion Studies."

\subsection{QUALITY ASSURANCE RECORDS}

The following are retained as Quality Assurance records:

- $\quad$ scientific notebook and/or an electronic database (e.g. Microsoft Access)

- the calibration certificates of the NIST traceable standards

- any Nonconformance Reports resulting from calibration

Calibration records governed by this TIP shall be maintained in the scientific notebook and/or appropriate electronic media.

\subsection{ASSOCIATED ACTIVITIES AND TIPS}

This TIP can be used in the activities of the of SIP "Metal Barrier Selection and Testing" (SIP-CM-01, WBS \# 1.2.2.5.1). In particular it may be used in

- Activity E-20-50, "Long Term Corrosion Studies"

- Activity E-20-47, "Thermogravimetric Studies"

Associated TIPs include:

- TIP-CM-03, "Electronic Weight-and-Dimensional-Data Entry in a Computer Database"

- $\quad$ TIP-CM-05, "User-Calibration of Fowler Ultra-Cal Mark III Digital Caliper"

\subsection{APPENDIX}

Standards laboratory certificate for metric weights. 


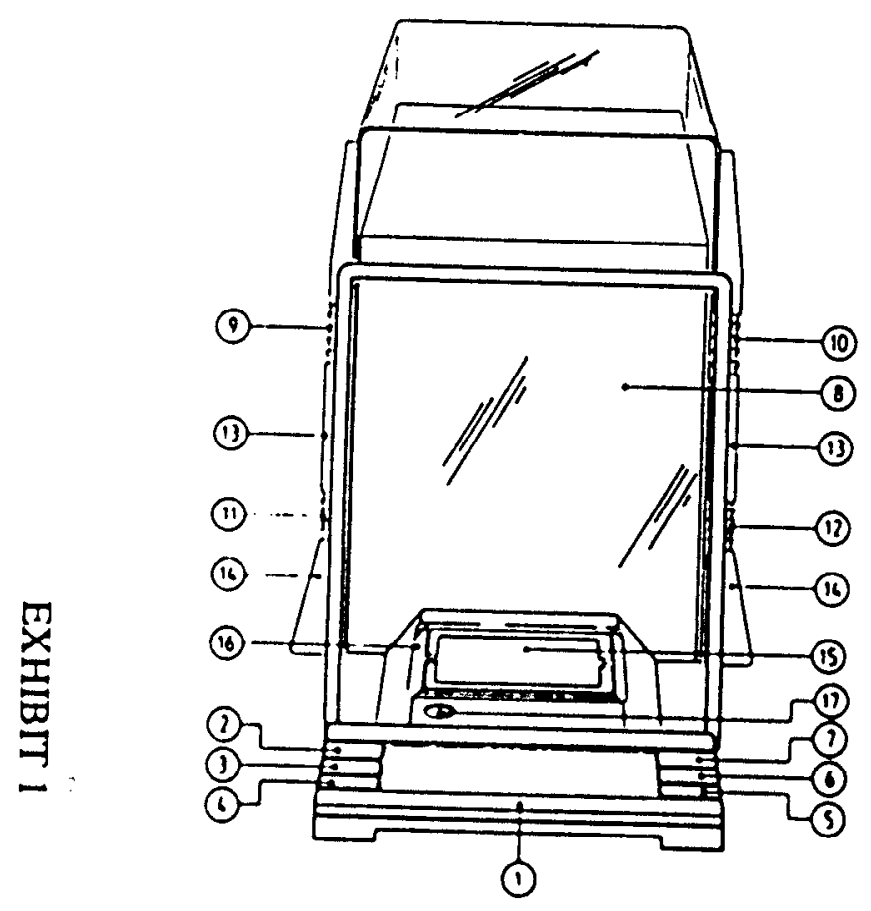

(2)

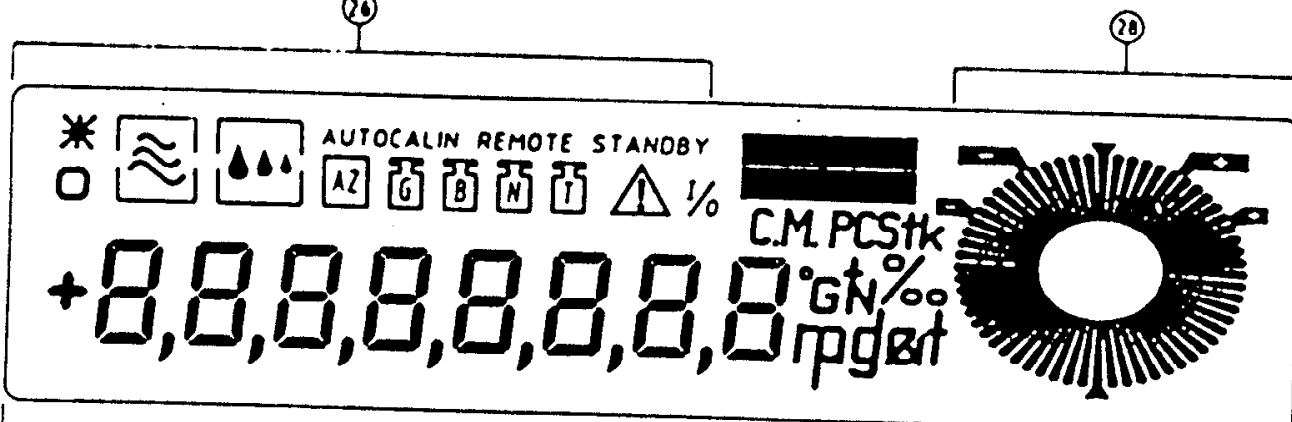

(1)
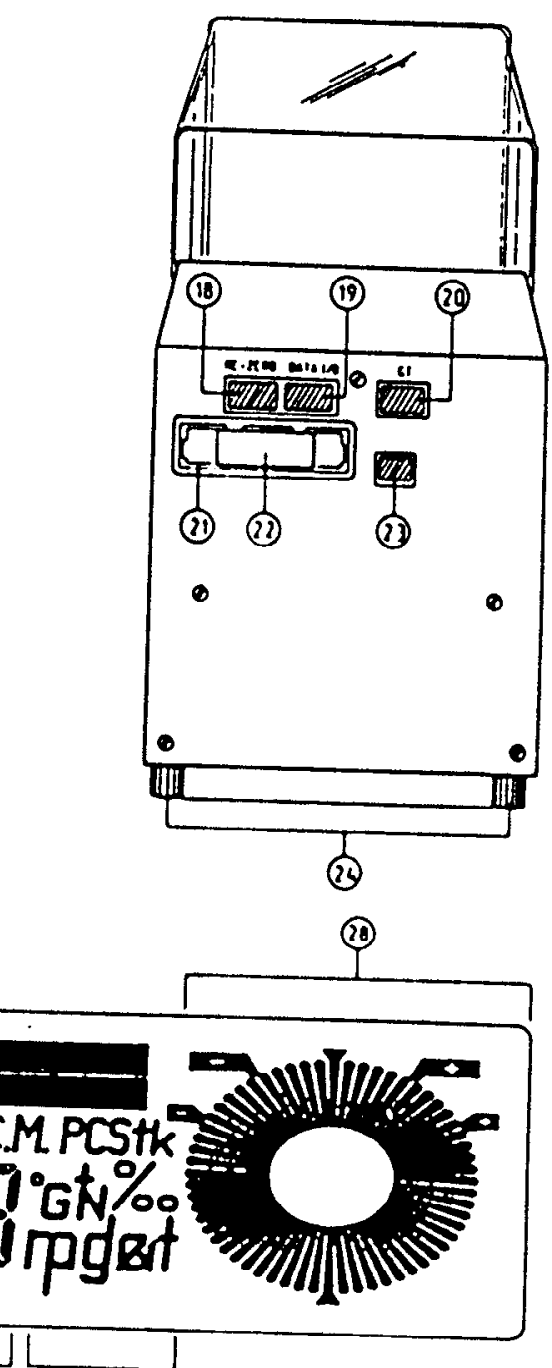

(37)
Key "Re-Zero", "Set", "On/Off"

2 Key "0.1/0.01 mg" (with dual-range balances only), "Cancel"

3 Key "Menu", "Configuration"

4 Key $\$$ "Select i"

5 Key 1 "Select 2"

6 Key "Print"

7 Key $\approx$

8 Glass draft shield

9 Coupling element

10 Coupling element

11 Coupling element

12 Coupling element

13 Door handle

14 Door drive handle

15 Weighing pan

16 Draft cover

17 Level

18 Connection for foot or hand switch and electrical contacts

19 Connection for data interface

20 Connection for METTLER GT units

21 Plug-in slot for program casselte

22 Program cassette

23 Connection for AC adapter

24 Screw feet

25

26

27

28
Digital display (VFD or LCD)

Status indicators

Weight units

METTLER DeltaTrac 


\section{Standards Laboratory Certificate}

METRIC WEIGHTS (Set of 18)

Manufacturer: Troemner

Range: .005 grams to 100 grams

Tested for: LLNL

Date tested: June 13, 1996

Recall No.: 4935818

Expires on: June 13, 1999

Serial No. : None

The weights identified above were tested to determine the individual mass values only. The values under the heading "Apparent Mass vs. Steel" on the attached page are those that the weights would appear to have when compared in an air density of $1.180 \mathrm{mg} / \mathrm{cm} 3$ (San Francisco average) against stainless steel standards (material density $8.0 \mathrm{~g} / \mathrm{cm} 3$ ). The average air density is based on information about the barometric pressure and relative humidity provided by the National Weather Service. The estimated average air density may differ by $+/-3 \%$ from the actual air density. Actual temperature, barometric pressure, and humidity were measured and used in the true mass calculations. "True Mass" values are those that the weights would appear to have in air of zero density, i.e., in a vacuum.

This weight set is expected to remain within the estimated uncertainties listed on the attached page for the duration of the certification interval provided it is not physically damaged.

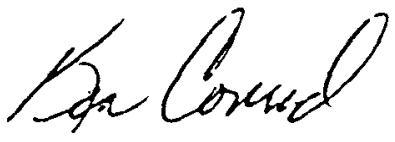

Cenified by: Ken Conrad, 1486

Reference Standards:

\begin{tabular}{ccc} 
I.D. Number & Description & Expires \\
\hline $7532 \mathrm{P}$ & Weight Set & $04 / 20 / 97$ \\
T1090 & Temperature & $10 / 11 / 96$ \\
C4020 & Humidity & $08 / 09 / 96$ \\
AH04291 & Pressure & $01 / 01 / 97$
\end{tabular}

Copy to:

Lawrence Livermore National Laboratory

P.O. Box 808

7000 East Ave.

Livermore, California 94550 
Recall No.: 4935818

Expires on: June 13, 1999

Tested for: LLNL

\begin{tabular}{ccc} 
& \multicolumn{2}{c}{ TRUE MASS } \\
Nominal & Value & \multicolumn{1}{c}{ DeV } \\
\hline 100.00 & 99.99978 & -0.22 \\
50.00 & 50.00018 & 0.18 \\
20.000 & 20.000073 & 0.073 \\
20.000 & 20.000073 & 0.073 \\
10.000 & 10.000009 & 0.009 \\
5.000 & 5.000032 & 0.032 \\
2.000 & 2.000029 & 0.029 \\
2.000 & 1.999994 & -0.006 \\
1.000 & 1.000002 & 0.002 \\
0.500 & 0.499985 & -0.015 \\
0.200 & 0.199981 & -0.019 \\
0.200 & 0.199983 & -0.017 \\
0.100 & 0.099992 & -0.008 \\
0.050 & 0.049992 & -0.008 \\
0.020 & 0.020005 & 0.005 \\
0.020 & 0.019989 & -0.011 \\
0.010 & 0.009996 & -0.004 \\
0.005 & 0.005008 & 0.008
\end{tabular}

APPARENT MASS VS STEEL Meas.

\begin{tabular}{l} 
Value \\
\hline 99.99947 \\
50.00003 \\
20.000013 \\
20.000013 \\
9.999978 \\
5.000017 \\
2.000023 \\
1.999988 \\
0.999999 \\
0.499985 \\
0.199981 \\
0.199983 \\
0.099992 \\
0.049992 \\
0.019999 \\
0.019983 \\
0.009993 \\
0.005007
\end{tabular}

Dev

-0.53
0.03
0.013
0.013
-0.022
0.017
0.023
-0.012
-0.001
-0.015
-0.019
-0.017
-0.008
-0.008
-0.001
-0.017
-0.007
0.007

Uncer.

0.50

0.20

0.06

0.06

0.06

0.05

0.04

0.04

0.04

0.03

0.03

0.03

0.01

0.01

0.01

0.01

0.01

0.01

$* * * * *$ Values in Grams $* * * * * *$

* Deviations in Milligrams *

Material and Assumed Density:

\begin{tabular}{lc} 
Material & $(\mathrm{g} / \mathrm{cm} 3)$ \\
\hline Stainless & 7.84 \\
Stainless & 8.0 \\
Aluminum & 2.7
\end{tabular}

\begin{tabular}{lr}
\multicolumn{2}{c}{ Range } \\
\hline 1.000 & 100.000 \\
0.050 & 0.500 \\
0.005 & 0.020
\end{tabular}

Apparent mass vs steel values were calculated using an air density of $1.18 \mathrm{mg} / \mathrm{cm} 3$ (San Francisco average) and true mass values were calculated using actual measured values for temperature, barometric pressure and humidity at time of test. 